\title{
Editorial
}

\section{Utilities Procurement - The New Priority in Public Procurement}

Utilities Procurement is a forgotten part of the European Public Procurement framework. The priority of EU institutions has been set to regulate the procurement of the public sector. However, utilities represent an essential component of the internal market of the EU and their procurement reflects on the need to ensure that the public sector aligns with utilities in their purchasing regulation.

Essentially the same changes have been effected by the $2014 \mathrm{EU}$ legislative framework for the Utilities Directive 2014/25/EU as for the Public Sector Directive 2014/24/EU. In order to take into account the flexibility required in the procurement of entities which operate in the Utilities sectors, there have been changes and amendments on issues specific to the Utilities Directive 2014/25/EU which provide for clarity and certainty.

There are new definitions for a number of concepts in Utilities procurement:

- regional authorities includes all authorities of the administrative units, listed non-exhaustively in NUTS 1 and 2, as referred to in Regulation (EC) No 1059/2003;

- local authorities, includes all authorities of the administrative units falling under NUTS 3 and smaller administrative units, as referred to in Regulation (EC) No 1059/2003;

- ancillary purchasing activities cover activities consisting in the provision of support to purchasing activities, in particular in the following forms: technical infrastructure enabling contracting entities to award public contracts or to conclude framework agreements for works, supplies or services; advice on the conduct or design of procurement procedures; preparation and management of procurement procedures on behalf and for the account of the contracting entity concerned;

- procurement service provider means a public or private body, which offers ancillary purchasing activities on the market;

- life cycle indicates all consecutive and/or interlinked stages, including research and development to be carried out, production, trading and its conditions, transport, use and maintenance, throughout the existence of the product or the works or the provision of the service, from raw material acquisition or generation of resources to disposal, clearance and end of service or utilisation;

- innovation means the implementation of a new or significantly improved product, service or process, including but not limited to production, building or construction processes, a new marketing method, or a new organisational method in business practices, workplace organisation or external relations, inter alia, with the purpose of helping to solve societal challenges or to support the Europe 2020 strategy for smart, sustainable and inclusive growth.

A new definition on conflicts of interest ${ }^{1}$ was established concerning the conflicts of interest and categories of affected persons but only in respect of contracting authorities which must appropriate measures to effectively prevent, identify and remedy conflicts of interest arising in the conduct of procurement procedures so as to avoid any distortion of competition and to ensure equal treatment of all economic operators. The concept of conflicts of

DOI: $10.21552 / \mathrm{epppl} / 2021 / 2 / 3$

1 Directive 2014/25/EU of the European Parliament and of the Council of 26 February 2014 on procurement by entities operating in the water, energy, transport and postal services sectors and repealing Directive 2004/17/EC [2014] OJ L 94/243, art 42. 
interest shall at least cover any situation where staff members of the contracting authority or of a procurement service provider acting on behalf of the contracting authority who are involved in the conduct of the procurement procedure or may influence the outcome of that procedure have, directly or indirectly, a financial, economic or other personal interest which might be perceived to compromise their impartiality and independence in the context of the procurement procedure.

The Utilities Directive 2014/25/EU introduced amended definitions for:

- candidate captures an economic operator that has sought an invitation or has been invited to take part in a restricted or negotiated procedure, in a competitive dialogue or in an innovation partnership;

- procurement document is regarded as any document produced or referred to by the contracting entity to describe or determine elements of the procurement or the procedure, including the contract notice, the periodic indicative notice or the notices on the existence of a qualification system where they are used as a means of calling for competition, the technical specifications, the descriptive document, proposed conditions of contract, formats for the presentation of documents by candidates and tenderers, information on generally applicable obligations and any additional documents;

- centralised purchasing activities cover activities conducted on a permanent basis, for the acquisition of supplies and/or services intended for contracting entities, or the award of contracts or the conclusion of framework agreements for works, supplies or services intended for contracting entities;

- central purchasing body means a contracting entity or a contracting authority which provide centralised purchasing activities and, possibly, ancillary purchasing activities. Procurement carried out by a central purchasing body in order to perform centralised purchasing activities shall be deemed to be procurement for the pursuit of activities in the gas and heat sector, the electricity production and distribution sector, the water sector, in transport services, in ports and airports, in postal services and for extraction of oil and gas and exploration for, or extraction of, coal or other solid fuels. The exclusion from the Utilities Procurement Directive for contracts awarded for purposes of resale or lease to third parties ${ }^{2}$ is not applicable to central purchasing bodies for performing centralised purchasing activities;

- supply covers generation, wholesale and retail activities.

The method for calculation of the estimated value of procurement was amended specifically to cover cases related to the separate operational units ${ }^{3}$ of a contracting entity, where account shall be taken of the total estimated value for all the individual operational units. Where a separate operational unit is totally or partially independently responsible for its procurement, the values may be estimated at the level of the unit in question.

There is a detailed provision of mixed procurement contracts covering the same activity and procurement covering several activities.

A mixed contract covering the same activity is a contract which has as its subject-matter two or more types of procurement for works, services or supplies.

Mixed contracts must be awarded in accordance with the provisions applicable to the type of procurement that characterises the main subject of the contract in question. For mixed contracts consisting partly of services and partly of supplies, and for mixed contracts consisting partly of services covered by the light regime as in the Public Sector Di-

\footnotetext{
Directive 2014/25/EU, art 18
}

Directive 2014/25/EU, art 16 
rective 2014/24/EU Annex XIV and partly of other services, the main subject shall be determined in accordance with which of the estimated values of the respective services or supplies is the highest.

Contracts which have as their subject-matter procurement covered by the Utilities Procurement Directive 2014/25/EU as well as procurement not covered by that Directive may be separated. Contracting entities may choose to award separate contracts for the separate parts or instead to award a single contract. Where the different parts of a given contract are objectively not separable, the applicable legal regime shall be determined on the basis of the main subject-matter of that contract.

If contracting entities choose to award separate contracts, the decision as to which legal regime applies to any one of the separate contracts shall be taken on the basis of the characteristics of the separate contract concerned.

If contracting entities choose to award a single contract, such single contact is regarded as a mixed contract irrespective of the value of the parts that would otherwise fall under a different legal regime and irrespective of which legal regime those parts would otherwise have been subject to. The consequence is that for the award of a singe contract, the Utilities Procurement Directive 2014/25/EU is applicable. There is an exception ${ }^{4}$ to that provision in cases of mixed contracts covering the same activity and involving defence or security aspects covered by Article 346 TFEU or Directive 2009/81/EC, in which cases the award of the relevant contract falls outside the Utilities Procurement Directive 2014/25/EU.

In the case of mixed contracts containing elements of supply, works and service contracts and of concessions, the mixed contract shall be awarded in accordance with the Utilities Procurement Directive 2014/25/EU, provided that the estimated value of the part of activities for the contract is equal to or greater than the relevant threshold values stipulated by Utilities Procurement Directive 2014/25/EU.

\section{Procurement Covering Several Activities}

For contracts intended to cover several activities, contracting entities may choose to award separate contracts for the purposes of each separate activity. The decision as to which rules apply to any one of such separate contracts shall be taken on the basis of the characteristics of the separate activity concerned and shall be subject to the rules applicable to the activity for which it is principally intended.

Contracting entities may choose to award a single contract for procurement covering several activities. The choice between awarding a single contract shall not be made with the objective of excluding the application of the Public Sector Procurement Directive 2014/24/EU or the Concessions Procurement Directive 2014/23/EU.

Contracts for which it is objectively impossible to determine the principal intention of one or all of their several activities, if one of the activities for which the contract is intended is subject to the Utilities Procurement Directive 2014/25/EU and the other to the Public Sector Procurement Directive 2014/24/EU, the contract shall be awarded in accordance with Public Sector Procurement Directive 2014/24/EU; if one of the activities for which the contract is intended is subject to the Utilities Procurement Directive 2014/25/EU and the other to Concessions Procurement Directive 2014/23/EU, the contract shall be awarded in accordance with Utilities Procurement Directive 2014/25/EU; if one of the activities for which the contract is intended is subject to this Directive and the other is not subject to any of the EU Procurement Directives, the contract shall be awarded in accordance with 
Utilities Procurement Directive 2014/25/EU.

\section{Special and Exclusive Rights}

There is explicit clarification of the concept of 'special and exclusive rights'. Special or exclusive rights means rights granted by a competent authority of a Member State by way of any legislative, regulatory or administrative provision the effect of which is to allow one or more entities to carry out activities in the gas and heat sector, the electricity production and distribution sector, the water sector, in transport services, in ports and airports, in postal services and for extraction of oil and gas and exploration for, or extraction of, coal or other solid fuels and substantially affects the ability of other entities to enter the relevant markets.

Rights which have been granted by means of procedures such as public procurement procedures or procedures ensuring adequate transparency and publicity has been ensured and where the granting of those rights was based on objective criteria are not considered as special or exclusive rights.

\section{Coverage of Utilities Procurement}

Non-economic services of general interest are excluded from Utilities procurement.

Exploration for oil or natural gas has been excluded from the Utilities Procurement Directive 2014/25/EU as the relevant sector is deemed to be be subject to a competitive environment thus rendering the Utilities Procurement Directive 2014/25/EU inapplicable. However, activities related to the extraction of oil or gas are subject to the Utilities Procurement Directive 2014/25/EU.

Public passenger transport services by rail or metro are excluded ${ }^{5}$ from the Utilities Procurement Directive 2014/25/EU.

The exclusion of passenger bus services under the Utilities Procurement Directive 2004/17/EU has been abolished. Entities providing bus transport services to the public, which were also excluded from the scope of the previous Utilities Directive 93/38 on the grounds that relevant activities were performed in a sufficiently competitive market and the need to preserve a multitude of specific arrangements applying to that sector cannot longer rely on that exemption.

Services ancillary ${ }^{6}$ to postal services previously covered by the Utilities Procurement Directive 2004/17/EU, and in particular, mail service management services (services both preceding and subsequent to dispatch, such as mailroom management services), addedvalue services linked to and provided entirely by electronic means (including the secure transmission of coded documents by electronic means, address management services and transmission of registered electronic mail), services concerning postal items such as direct mail bearing no address, financial services including in particular postal money orders and postal giro transfers, philatelic services, and finally logistics services (services combining physical delivery or warehousing with other non-postal functions), are excluded from the Utilities Procurement Directive 2014/25/EU.

Postal services such as poste restante, mail box rental, post counter services fall under the remit of the light procurement regime which is similar to the Public Sector Procure- 
ment Directive 2014/24/EU.

\section{Contracts Between Contracting Entities Within Controlling Entities}

The Utilities Procurement Directive 2014/25/EU exempts ${ }^{7}$ from tendering requirements contracts between contracting authorities, but not contracting entities or public undertakings, and legal entities upon which the former exercise single or joint control that is similar to the control that they exercise over their own departments and the latter performs more than $80 \%$ of the activities for the benefit of the former by other legal persons controlled by that contracting authority; and there is no direct private capital participation in the controlled legal entity with the exception of non-controlling and non-blocking forms of private capital participation required by national legislative provisions which do not exert a decisive influence on the controlled legal person.

The controlled entity by single or multiple contracting authorities is exempt from applying the Public Procurement Directive in awarding a contract to its controlling contracting authority, or to another legal entity controlled by the same contracting authority ${ }^{8}$, provided that there is no direct private capital participation in the legal person being awarded the public contract with the exception of non-controlling and non-blocking forms of private capital participation required by national legislative provisions which do not exert a decisive influence on the controlled legal person.

The exemption of public-public co-operation which has been established in the Public Sector Procurement Directive 2014/24/EU ${ }^{9}$ is also provided for under the Utilities Procurement Directive 2014/25/EU ${ }^{10}$, however it covers only contracting authorities and is not extended to contracting entities ${ }^{11}$ nor public undertakings ${ }^{12}$. The conditions of co-cooperation remain similar between the Public Sector Procurement Directive 2014/24/EU and the Utilities Procurement Directive 2014/25/EU. A contract concluded exclusively between two or more contracting authorities is not deemed as a public procurement contract if it establishes or implements a cooperation between the participating contracting authorities with the aim of ensuring that public services they have to perform are provided with a view to achieving objectives they have in common; and the implementation of that cooperation is governed solely by considerations relating to the public interest; and finally the participating contracting authorities perform on the open market less than $20 \%$ of the activities concerned by the cooperation.

There are new exclusions envisaged in the 2014 Utilities Procurement Directive.

Public contracts and design contests which the contracting entity awards in accordance with procurement rules provided by an international organisation or international financing institution ${ }^{13}$ which finances these contracts or design contests, are excluded from the Utilities Procurement Directive 2014/25/EU. Contracts or design contests which are co-fi-

7 Directive 2014/25/EU, art 28

8 Directive 2014/24/EU, art 12(2).

9 Directive 2014/24/EU, art 12(4).

10 Directive 2014/25/EU, art 28(4).

11 Directive 2014/25/EU, art 4(1) specifies as contracting entities are contracting authorities or public undertakings or entities which operate on the basis of special or exclusive rights granted by a competent authority of a Member State and which pursue one of the activities in the gas and heat sector, the electricity production and distribution sector, the water sector, in transport services, in ports and airports, in postal services and for extraction of oil and gas and exploration for, or extraction of, coal or other solid fuels and substantially affects the ability of other entities to enter the relevant markets.

12 Directive 2014/25/EU, art 4(2) specifies Public undertakings are undertaking over which the contracting authorities may exercise directly or indirectly a dominant influence by virtue of their ownership of it, their financial participation therein, or the rules which govern it.

13 Directive 2014/25/EU, art 20 
nanced the most part by an international organisation or international financing institutions are subject to applicable procurement procedures agreed by the parties.

\section{Exclusion Criteria}

The mandatory exclusion criteria include conviction by final judgment for one of the following reasons: participation in a criminal organisation; corruption; fraud; terrorist offences or offences linked to terrorist activities; money laundering or terrorist financing; child labour and other forms of human trafficking; non-fulfilment of obligations relating to the payment of taxes or social security contributions specified in the Public Sector Procurement Directive 2014/24/EU are obligatory under the Utilities Procurement Directive 2014/25/EU only in cases where the contracting entity is a contracting authority ${ }^{14}$. Contracting entities or public undertakings may apply these exclusion criteria.

Contracting authorities, contracting entities and public undertakings may be required by Member States to apply exclusion criteria covering the discretionary grounds for exclusion of economic operators specified in the Public Sector Procurement Directive 2014/24/EU and include violations of applicable obligations referred to in Article 18(2); bankruptcy or subject of insolvency or winding-up proceedings; grave professional misconduct; distortion of competition; conflict of interest; distortion of competition from prior involvement with the contracting authority; significant or persistent deficiencies in the performance of public contracts; serious misrepresentation; undue influence of the decision making process of contracting authorities;

Re-Establishment of reliability follows common rules with the Public Sector Procurement Directive 2014/24/EU in all cases of contracting authorities, contracting entities and public undertakings under the Utilities Procurement Directive 2014/25/EU. If a contracting authority or a contracting entities or a public undertakings has sufficient evidence by any economic operator falling under the mandatory or discretionary exclusion grounds in public procurement procedures that measures have been taken by that economic operator to demonstrate its reliability despite the existence of a relevant ground for exclusion, the economic operator concerned shall not be excluded from the procurement procedure.

Measures that have been taken by economic operators seeking re-establishment of reliability must be evaluated taking into account the gravity and particular circumstances of the criminal offence or misconduct and must prove that the economic operator has paid or undertaken to pay compensation in respect of any damage caused by the criminal offence or misconduct, clarified the facts and circumstances in a comprehensive manner by actively collaborating with the investigating authorities and taken concrete technical, organisational and personnel measures that are appropriate to prevent further criminal offences or misconduct.

Member States must determine by law, regulation or administrative provision the maximum period of exclusion of economic operators who fall under the mandatory or discretionary exclusion grounds, if no reliability measures have been taken or proven sufficient. Where the period of exclusion has not been set by final judgment of the relevant Member State, that period shall not exceed five years from the date of the conviction by final judgment in the mandatory exclusion grounds cases and three years from the date of the relevant event in the discretionary exclusion grounds cases. 


\section{Light Regime Procurement}

For contracts related to social and other specific services listed in Annex XVII of the Utilities Procurement Directive 2014/25/EU, the threshold is $€ 1$ million. Such services include health, social and related services, administrative social, educational, healthcare and cultural services, compulsory social security services ; benefit services, community, social and personal services including services furnished by trade unions, political organisations, youth associations and other membership organisation services; religious services; hotel and restaurant services; legal and administrative government services; provision of services to the community; prison related services; public security and rescue services; investigation and security services; international services such as services provided by extra-territorial organisations and bodies and services specific to international organisations and bodies; postal services; miscellaneous services related to tyre-remoulding services and blacksmith services.

The light procurement regime for such services implies only ex-ante ex-post publicity requirements plus adherence to the principle of non-discrimination principle. Member States have the choice to apply only the best price-quality ratio (BPQR) which must be assessed on the basis of award criteria linked to the subject-matter of the contract.

\section{Innovation Partnership}

The Innovation Partnership ${ }^{15}$ is an award procedure designed to improve market interest by combining a contract which has the object of research with a purchase followed-up contract, provided that the research result fulfils pre-defined performance levels. Innovation partnerships are structured in successive phases similar to the procedure of competitive negotiations with intermediate targets and payments and cut-off options.

\section{Activities Directly Exposed to Competition}

The material conditions related to any utilities activities directly exposed to competition ${ }^{16}$ remain unchanged by the Utilities Procurement Directive 2014/25/EU. If an activity in the gas and heat sector, the electricity production and distribution sector, the water sector, in transport services, in ports and airports, in postal services and for extraction of oil and gas and exploration for, or extraction of, coal or other solid fuels is directly exposed to competition on markets to which access is not restricted, after a request by Member States or contracting entities ${ }^{17}$ engaged in such activity and an assessment by the European Commission that the activity is directly exposed to competition on markets to which access is not restricted, contracts intended to enable an activity are not be subject to the Utilities Procurement Directive 2014/25/EU.

Access to a market is presumed not to be restricted if Member States have implemented and applied the EU law listed in Annex $\mathrm{III}^{18}$ of the Utilities Procurement Directive 2014/25/EU. The Utilities Directive has updated the list of EU legislation giving legal pre-

15 Directive 2014/25/EU, art 49

16 Directive 2014/25/EU, art 34

17 The procedural framework of Member States or contracting entities to request the non-applicability of the Utilities Procurement Directive 2014/25/EU to activities directly exposed to competition is regulated by art 35 of the Utilities Procurement Directive 2014/25/EU which has been amended to provide Uniform and more flexible deadlines to Member States or contracting entities.

18 For transport or distribution of gas or heat, Directive 2009/73/EC of the European Parliament and of the Council of 13 July 2009 concerning common rules for the internal market in natural gas and repealing Directive 2003/55/EC [2009] OJ L 211/94; for production, transmission or distribution of electricity, Directive 2009/72/EC of the European Parliament and of the Council of 13 July 2009 concerning common rules for the internal market in electricity and repealing Directive 2003/54/EC [2009] OJ L 211/55; For contracting entities in the field of rail services, international rail passenger transport, rail freight transport, Directive 2012/34/EU of the European Parliament and of the Council of 21 November 2012 establishing a single European railway area [2012] OJ L 343/32 
sumption of free access by adding Directive 2012/34/EEC to cover the markets of rail freight transport and international passenger transport.

There is a toolbox approach created for the Utilities Procurement Directive 2014/25/EU in relation to the procurement procedures. Member State systems can provide the three basic forms of procedure which already exist under the Public Sector Procurement Directive 2014/24/EU: open procedures, restricted procedures as well as competitive negotiated procedures. They can further provide competitive dialogue and the innovation partnership.

As in the Public Sector Procurement Directive, the Utilities Procurement Directive 2014/25/EU establishes preliminary market consultation, where prior involvement of candidates or tenderers is allowed. Where a candidate or tenderer or an undertaking related to a candidate or tenderer has advised the contracting entity or has otherwise been involved in the preparation of the procurement procedure, the contracting authority shall take appropriate measures to ensure that competition is not distorted by the participation of that candidate or tenderer.

Contracting authorities and contacting entities under the Utilities Procurement Directive 2014/25/EU have at their disposal a set of six specific procurement procedures intended for aggregated and electronic procurement: framework agreements, central purchasing bodies, joint procurement, dynamic purchasing systems, electronic auctions, electronic catalogues. There are shorter time-limits for the open procedure and an option for the urgent open procedure. There are also shorter time-limits for the restricted and negotiated procedure, with no accumulation of shortening time-limits. In open procedures, contracting entities may decide to examine tenders before verifying the fulfilment of the selection criteria. Compared to the previous Utilities Procurement Directive 2004/17/EC these procedures have been improved and clarified, particularly with a view to facilitating e-procurement. The use of electronic procurement in particular in relation to the transmission of notices and the availability of the all procurement documents is mandatory since October 2018.

Framework agreements should not exceed 8 years. The award of framework agreements is to be made with additional procedural safeguards on objective rules and criteria of their formation, however without any further alignment with the Public Sector Procurement Directive 2014/24/EU.

In order to award contracts under a dynamic purchasing system, contracting entities must now follow the rules of the restricted procedure instead of open procedure (Article 34 Public Sector Directive 2014/24/EU and Article 52 Utilities Procurement Directive 2014/25/EU). The dynamic purchasing system shall not contain a maximum duration period and candidates who satisfy the selection criteria shall be admitted to the dynamic purchasing system, and the number of candidates to be admitted to the system shall not be limited. The dynamic purchasing system must allow economic operators to seek entry at any point during its duration. Evaluation of tenders from economic operators must be accomplished with 10 working days, without any indicative tenders or simplified notices, features which made the previous regime under Directive 2014/17 /EU difficult to operate.

Electronic catalogues represent standardised formats for presentation of tenders. There are new rules regulating the formatting of electronic catalogues. Member States may require use of e-catalogues for specific procurements and have the power to make their format and standards mandatory. E-catalogues can be utilised in particular for framework agreements and dynamic purchasing systems. There is specific provision of e-catalogues when used within framework agreements, where resubmission of updated catalogues is allowed before the award of new contracts. For this purpose, adequate time must be given between notification of the need for update and collection of bid information. 
Where tenders appear to be abnormally low in relation to the works, supplies or services, the contracting entity shall require economic operators to explain: ${ }^{19}$

- the price or costs proposed in the tender and in particular the economics of the manufacturing process, of the services provided or of the construction method; or

- the technical solutions chosen or any exceptionally favourable conditions available to the tenderer for the supply of the products or services or for the execution of the work; or

- the originality of the supplies, services or work proposed by the tenderer.

Abnormally low tenders may be the result of non-compliance with responsible procurement requirements ${ }^{20}$, which must lead to exclusion of the tenderer from the procurement process or the result of non-compliance with subcontractor obligations ${ }^{21}$ or reflect on the possibility of the tenderer having obtained State aid, which could lead to exclusion of the tenderer from the procurement process if the latter cannot prove the compatibility of the State aid received.

The Utilities Procurement Directive 2014/25/EU maintains the detailed regulation of tenders comprising products originating in third countries which do not have either multilateral or bilateral relations with the European Union as the previous Directive 2014/17/EU in specifying market access conditions for undertakings ${ }^{22}$ and relations with those countries $^{23}$.

There is the option for Member States to establish a system for direct payment for subcontractors $^{24}$ in the same regulatory manner as in the Public Sector Procurement Directive 2014/24/EU.

A modification of a contract or a framework agreement during its term shall be considered as substantial where it renders the contract or the framework agreement materially different in character from the one initially concluded ${ }^{25}$. A modification shall not be considered to be substantial where the following cumulative conditions are fulfilled and in particular, the need for modification has been brought about by circumstances which a diligent contracting entity could not foresee; and that the modification does not alter the overall nature of the contract. The Utilities Procurement Directive 2014/25/EU specifies that there is the threat of termination of contracts when a modification to that contract constitutes a new award ${ }^{26}$.

For the award of contracts for social and other specific services ${ }^{27}$, public contracts for social and other specific services with a contract threshold value of $€ 1$ million listed in Annex XVII shall be awarded in accordance with more flexible regulation which covers ex ante and ex post publicity, as in the Public Sector Procurement Directive 2014/24/EU.

All Public Procurement Directives benefit from the principles of discretion and flexibility in their application by Member States. Discretion of Member States in applying public procurement law is surrogate to the principle of proportionality. The flexibility of the pub-

Directive 2014/25/EU, art 84

Directive 2014/25/EU, art 36(2) referring to standards in the fields of environmental, social and labour law established by EU law, national law, collective agreements or by the international environmental, social and labour law standards.

Directive 2014/25/EU, art 88.

Directive 2014/25/EU, art 85

Directive 2014/25/EU, art 86

Directive 2014/25/EU, art 88

Directive 2014/25/EU, art 89

Directive 2014/25/EU, art 90

Directive 2014/25/EU, art 91. 
lic procurement regulatory regime is reflected in important recent case-law developments, in particular case-law on the definition of contracting authorities, the use of award procedures and award criteria, and the possibility for contracting authorities to use environmental and social considerations as criteria for the award of public contracts. Further, flexibility underpins the relaxation of the competitive tendering regime and the disengagement of the public procurement rules in industries that operate under competitive conditions in the utilities sectors indicate the links between procurement regulation and anti-trust. The non-applicability of the regime to telecommunications entities is an important development indicative of the future legal and regulatory blueprints.

Professor Christopher Bovis FRSA 